\title{
Socially distributed perception: GRACE plays social tag at AAAI 2005
}

Marek P. Michalowski • Selma Šabanović .

Carl DiSalvo • Dídac Busquets • Laura M. Hiatt •

Nik A. Melchior · Reid Simmons

Published online: 14 April 2007

(C) Springer Science+Business Media, LLC 2007

Erratum to: Auton Robot

DOI 10.1007/s10514-006-9015-6

The original version of this article unfortunately contained a mistake. The spelling of Dídac Busquets' name was incorrect.

The online version of the original article can be found at http://dx.doi.org/10.1007/s10514-006-9015-6.

M.P. Michalowski $(\varangle)$ - C. DiSalvo · D. Busquets · L.M. Hiatt ·

N.A. Melchior · R. Simmons

Carnegie Mellon University, Pittsburgh, PA 15213, USA

S. Šabanović

Rensselaer Polytechnic Institute, Troy, NY 12180, USA 